\title{
A landscape approach to conservation and development in the Central Indian Highlands
}

\author{
Ruth DeFries $^{1} \cdot$ Sandeep Sharma $^{2} \cdot$ Trishna Dutta $^{1}$
}

Received: 13 June 2016/Accepted: 15 June 2016/Published online: 18 July 2016

(C) Springer-Verlag Berlin Heidelberg 2016

The Central Indian Highlands is a microcosm that illustrates the intertwined challenges of conservation, development, and social equity in a rapidly emerging economy. In this special issue, we seek to apply the academic discourses of landscape-level management (Sayer et al. 2013) and conservation-development debates (Fisher et al. 2014) to the ground-level realities of this globally important landscape. As in many places around the world, the unresolved question of how to simultaneously improve local livelihoods, meet national-level development needs, and achieve conservation goals takes on urgency as current decisions are paving the future pathway for people and biodiversity in this landscape.

The late-nineteenth century British forest officer and avid hunter and explorer, James Forsyth, identified the Central Indian Highlands as the biogeographic region "in the very centre of India" where "several of the great rivers of India have their first sources ... and pour their waters into the sea on either side of the peninsula" (Forsyth 1871). Gajbhiye and Mandal (2000) define the central highlands as an Agro-Ecological Region covering approximately 25 million hectares or $7.6 \%$ of the total land area of the country (Fig. 1). The region spans 34 administrative districts across three states (Madhya Pradesh, Maharashtra, and Chhattisgarh). It is home to 54 million people (Government of India 2011): tribal groups with a deep history of forest-dependent cultures, small-scale farmers,

Ruth DeFries

rd2402@columbia.edi

1 Department of Ecology, Evolution, and Environmental Biology, Columbia University, New York, NY 10027, USA

2 Smithsonian Conservation Biology Institute, Washington, DC, USA and growing urban populations. About 70 percent of the population is rural with high dependency on forests for fuelwood, fodder, and income from forest products.

Tigers are an iconic feature of the landscape. Their conservation is the primary goal for the network of 32 protected areas, some connected by corridors of remaining forest. The network enables tigers to persist amidst expansion of infrastructure, forest degradation, and other human pressures. The landscape supports about $30 \%$ of the total tiger population in India (Jhala et al. 2011) and has been identified as a Global Priority Landscape for tiger conservation (Sanderson et al. 2010).

While much of the previous research in this landscape has focused on ecology and conservation within protected areas, e.g., (Schaller 2009), this special issue takes a holistic view of the landscape by focusing on areas outside protected area boundaries. The landscape provides livelihoods for local people, land for agriculture, habitat for wildlife, timber, and water for human consumption downstream. These demands on the landscape often compete. As is the case elsewhere in the world, there is no clear pathway to reconcile different priorities for the landscape or to manage the landscape as a whole unit.

Papers in this special issue collectively address several themes that reflect the challenges confronting this landscape. One set of papers addresses human interactions with forests and wildlife outside protected areas. Agarwala et al. (2016) show that human use of forests alters long-term forest composition and structure. Miller et al. (2016) confirm high rates of livestock predation outside a protected area and map high-risk areas. Awasthi et al. (2016) conclude that ungulate densities in the core of a protected area are higher than in multiple-use buffers outside. Borah et al. (2016) identify the importance of prey densities and human disturbance for tiger presence in a corridor between 


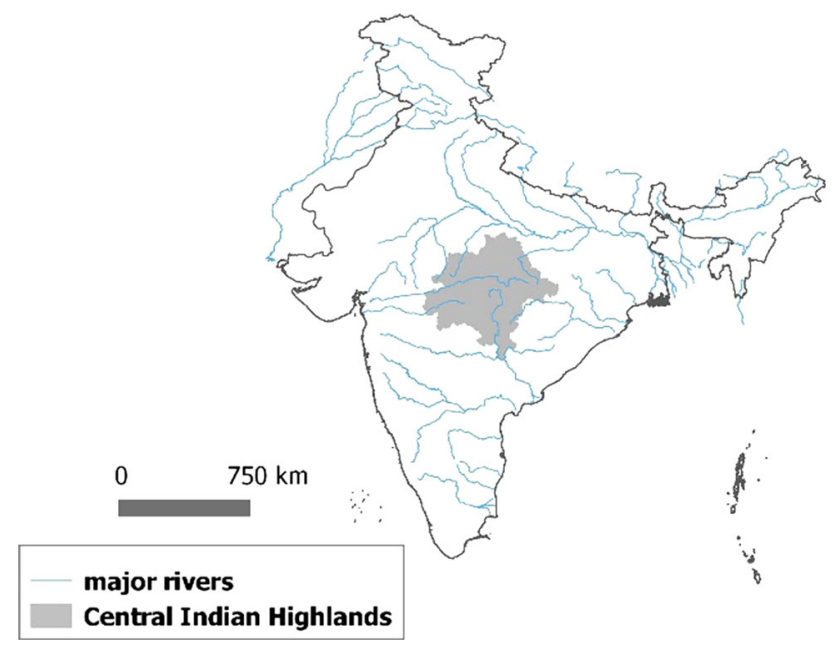

Fig. 1 Location of Central Indian Highlands and major rivers

protected areas, while Dutta et al. (2016) map the opportunities for connectivity between protected areas throughout the landscape despite high human presence. Two additional papers assess the provisions provided by the landscape for agricultural production (Mondal et al. 2016) and water supply for irrigation, urban areas, and other downstream uses (Clark et al. 2016). Another set of papers examines participation of local communities and social equity. Kashwan (2016) and Sekar (2016) survey local communities and illustrate the historical legacies of unbalanced power structures in resettlement of villages from protected areas. Macura et al. (2016), Read (2016), and Fleischman (2016) analyze effectiveness of existing management efforts and forest governance to address these difficult challenges and enable local communities to participate in and benefit from conservation. Seidensticker (2016) synthesizes possible solutions to reconcile conservation and development, including the development of future landscape scenarios with participation from multiple stakeholders, smart green infrastructure, and scaling-up from local interventions to achieve landscape-scale impacts.

This diverse collection of papers points toward several considerations for protected area managers, conservation practitioners, the research community, and others working toward a promising future for wildlife and people of the Central Indian Highlands:

- The goals and aspirations from multiple perspectivesincluding wildlife conservationists, historically marginalized communities, and those working toward economic development-need to be inclusively integrated in a future vision for the landscape. All of these perspectives are valid, and each has priorities that need to be accommodated for a bright future.
- Landscape-level processes, for example the movement of water from the headwaters to downstream users and the movement of wildlife across forested corridors, are essential to maintain functions that support people and wildlife. Effectiveness of development decisions and conservation actions depends on maintaining these landscape functions. Such a goal is complicated by the reality that landscape-level management does not mesh with the jurisdictions of those with authority to make decisions.

- Finally, a framework that integrates social, economic, and ecological viewpoints is fundamental for decisions that affect people and wildlife. While integrated frameworks are popular in the academic literature, e.g., (Tallis et al. 2008), implementation on the ground is exceedingly difficult and often runs counter to management structures. An integrated framework depends on including a broad range of expertise and multiple viewpoints at all levels of management in government, non-government entities, and research.

These three considerations apply particularly to the Central Indian Highlands where people and wildlife coexist in close proximity, and India's economic development is proceeding at a rapid pace. The same considerations, in different contexts, likely apply to the management of many landscapes throughout the world.

\section{References}

Agarwala M, DeFries R, Qureshi Q, Jhala Y (2016) Changes in dry tropical forests in Central India with human use. Reg Environ Change 16(S1):S5-S15. doi:10.1007/s10113-015-0903-1

Awasthi N, Kumar U, Qureshi Q, Pradhan A, Chauhan J, Jhala Y (2016) Effect of human use, season and habitat on ungulate density in Kanha Tiger Reserve, Madhya Pradesh, India. Reg Environ Change 16(S1):S31-S41. doi:10.1007/s10113-0160953-z

Borah J, Jena J, Yumnam B, Puia L (2016) Carnivores in corridors: estimating tiger occupancy in Kanha-Pench corridor, Madhya Pradesh, India. Reg Environ Change 16(S1):S43-S52. doi:10. 1007/s10113-015-0904-0

Clark B, DeFries R, Krishnaswamy J (2016) Intra-annual dynamics of water stress in the central Indian Highlands from 2002 to 2012. Reg Environ Change 16(S1):S83-S95. doi:10.1007/s10113-016$1017-0$

Dutta T, Sharma S, Roy PS, McRae B, DeFries R (2016) Connecting the dots: mapping habitat connectivity for tiger in Central India. Reg Environ Change 16(S1):S53-S67. doi:10.1007/s10113-0150877-z

Fisher B, Balmford A, Ferraro PJ, Glew L, Mascia M, Naidoo R, Ricketts TH (2014) Moving Rio forward and avoiding 10 more years with little evidence for effective conservation policy. Conserv Biol 28:880-882. doi:10.1111/cobi.12221

Fleischman F (2016) Understanding India's forest bureaucracy: a review. Reg Environ Change 16(S1):S153-S165. doi:10.1007/ s10113-015-0844-8 
Forsyth J (1871) The highlands of central India, vol 16. Chapman \& Hall, London

Gajbhiye K, Mandal C (2000) Agro-ecological zones, their soil resource and cropping systems. Status of Farm Mechanization in India, cropping systems, status of farm mechanization in India, pp 1-32

Government of India (2011) 2011 Census Data, Ministry of Home Affairs, Office of the Registrar General and Census Commissioner, New Delhi, India

Jhala YV, Qureshi Q, Gopal R, Sinha PR, (2011) Status of tigers, copredators and prey in India, TR 2011.003. National Tiger Conservation Authority, New Delhi and Wildlife Institute of India, Dehradun, p 302

Kashwan P (2016) Power asymmetries and institutions: landscape conservation in central India. Reg Environ Change 16(S1):S97S109. doi:10.1007/s10113-015-0925-8

Macura B, Secco L, Pisani E, Pullin A, Reyes-Garcia V (2016) All that glitters in not gold: the effect of top-down participation on conservation knowledge, attitudes and institutional trust in a Central Indian tiger reserve. Reg Environ Change 16(S1):S125S140. doi:10.1007/s10113-016-0978-3

Miller JR, Jhala YV, Jena J (2016) Livestock losses and hotspots of attack from tigers and leopards in Kanha Tiger Reserve, Central India. Reg Environ Change 16(S1):S17-S29. doi:10.1007/ s10113-015-0871-5

Mondal P, Jain M, Zukowski M, Galford G, DeFries R (2016) Quantifying fluctuations in winter cropped area in the Central Indian Highland landscape. Reg Environ Change 16(S1):S69S82. doi:10.1007/s10113-016-0946-y

Read DJ (2016) Legitimacy, access, and the gridlock of tiger conservation: lessons from Melghat and the history of central
India. Reg Environ Change 16(S1):S141-S151. doi:10.1007/ s10113-015-0780-7

Sanderson EW, Forrest J, Louckes CJ, Ginsberg JR, Dinerstein E, Seidensticker J, Leimbruber P, Songer M, Heydlauff A, O'Brien TG, Bryja G, Klenzendorf S, Wikramanayake ED (2010) Setting priorities for conservation and recovery of wild tigers: 2005-2015. In: Tilson R, Nyhus PJ (eds) Tigers of the world: the science, politics and conservation of Panthera tigris. Academic Press, London, pp 143-161

Sayer J, Sunderland T, Ghazoul J, Pfund J-L, Sheil D, Mijaard E, Venter M, Boedhihartono A, Day M, Garcia C, Oosten C, Buck L (2013) Ten principles for a landscape approach to reconciling agriculture, conservation, and other competing land uses. Proc Natl Acad Sci 110:8349-8356. doi:10.1073/pnas.1210595110

Schaller GB (2009) The deer and the tiger. University of Chicago Press, Chicago

Seidensticker J (2016) Biodiversity resilience in the Central Indian Highlands is contingent on maintaining and recovering landscape connectivity: the tiger as a case study. Reg Environ Change 16(S1):S167-S179. doi:10.1007/s10113-015-0846-6

Sekar N (2016) Tigers, Tribes, and Bureaucrats: the voluntariness and socioeconomic consequences of village relocations from Melghat Tiger Reserve, India. Reg Environ Change 16(S1):S111S123. doi:10.1007/s10113-015-0913-z

Tallis H, Kareiva P, Marvier M, Chang A (2008) An ecosystem services framework to support both practical conservation and economic development. Proc Natl Acad Sci 105:9457-9464. doi:10.1073/pnas.0705797105 